Supporting Information

\title{
Highly Exfoliated Graphene Oxide with Enhanced Carbonyl Content and Facile Amine Functionalization for Biomedical Applications
}

Saifon Kullyakool', Alongkot Treetong ${ }^{\dagger}$, Siriwat Soontaranon ${ }^{\ddagger}$ and Kritapas Laohhasurayotint, *

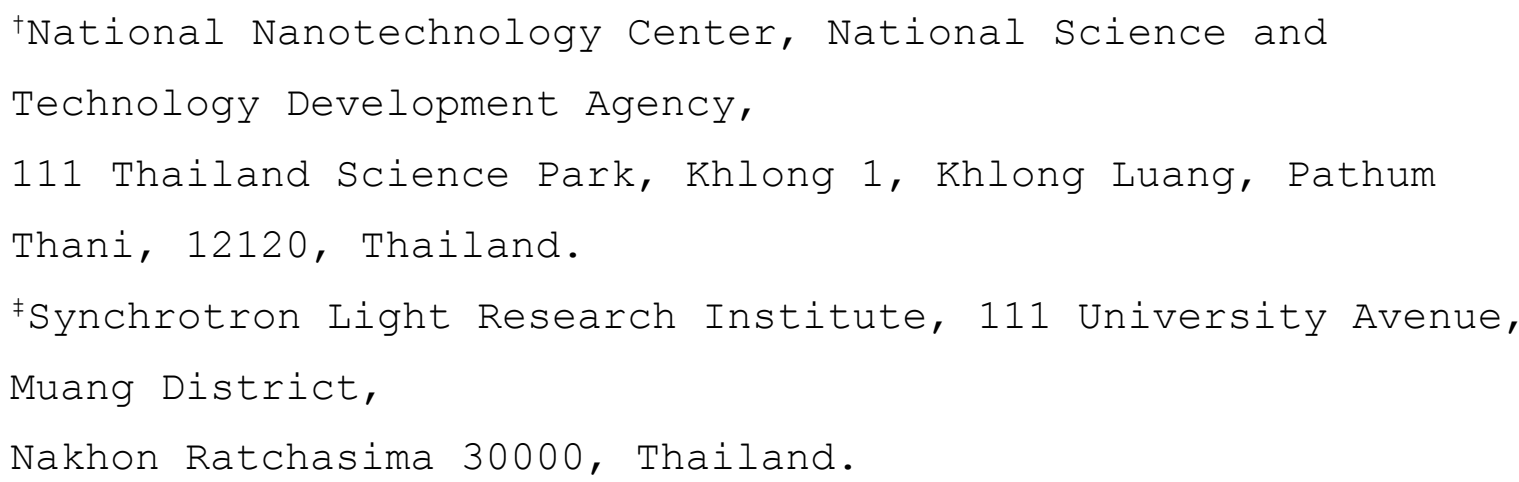

*Correspondence E-mail: kritapasenanotec.or.th 


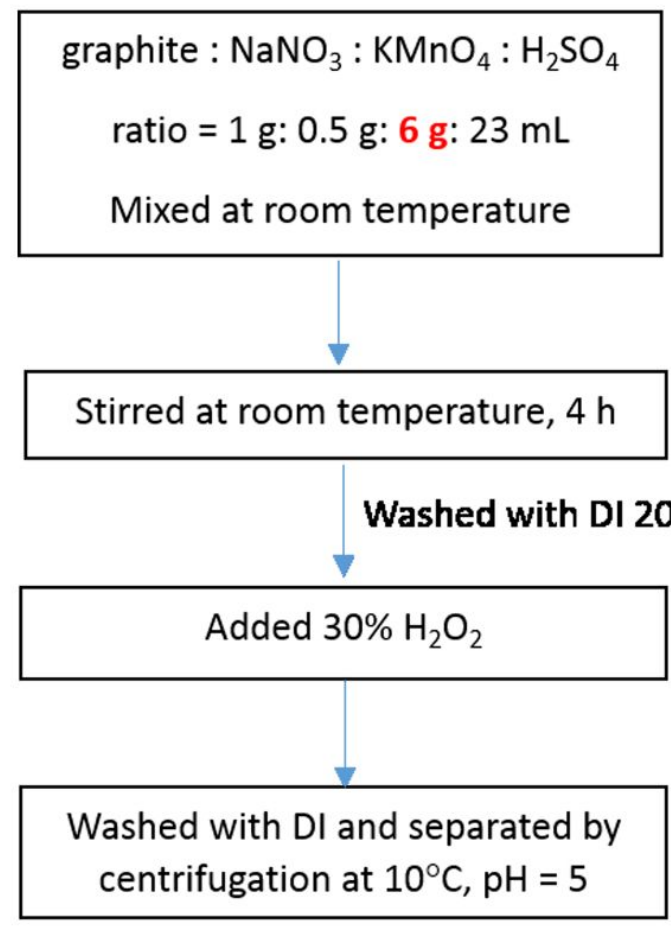

(a)

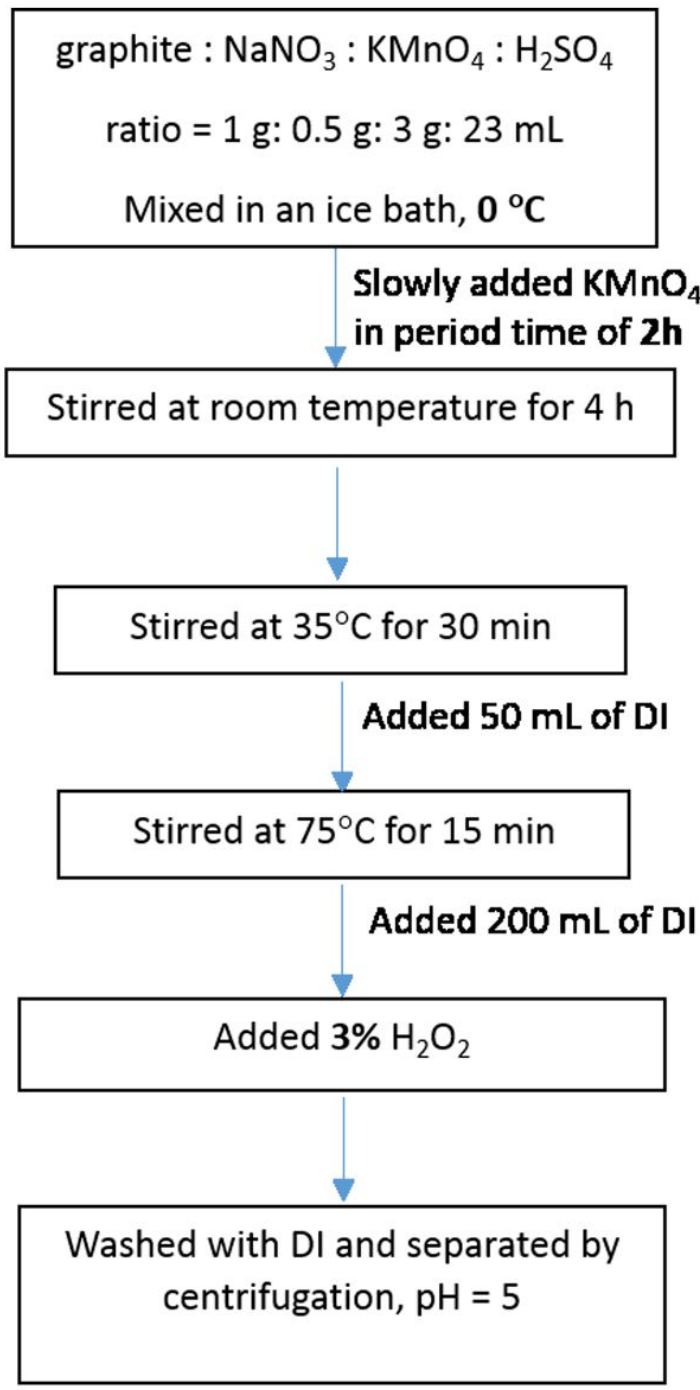

(b)

Figure S1. The synthetic methods for $\operatorname{HEGO(a)~and~GOHu~(b).~}$ 

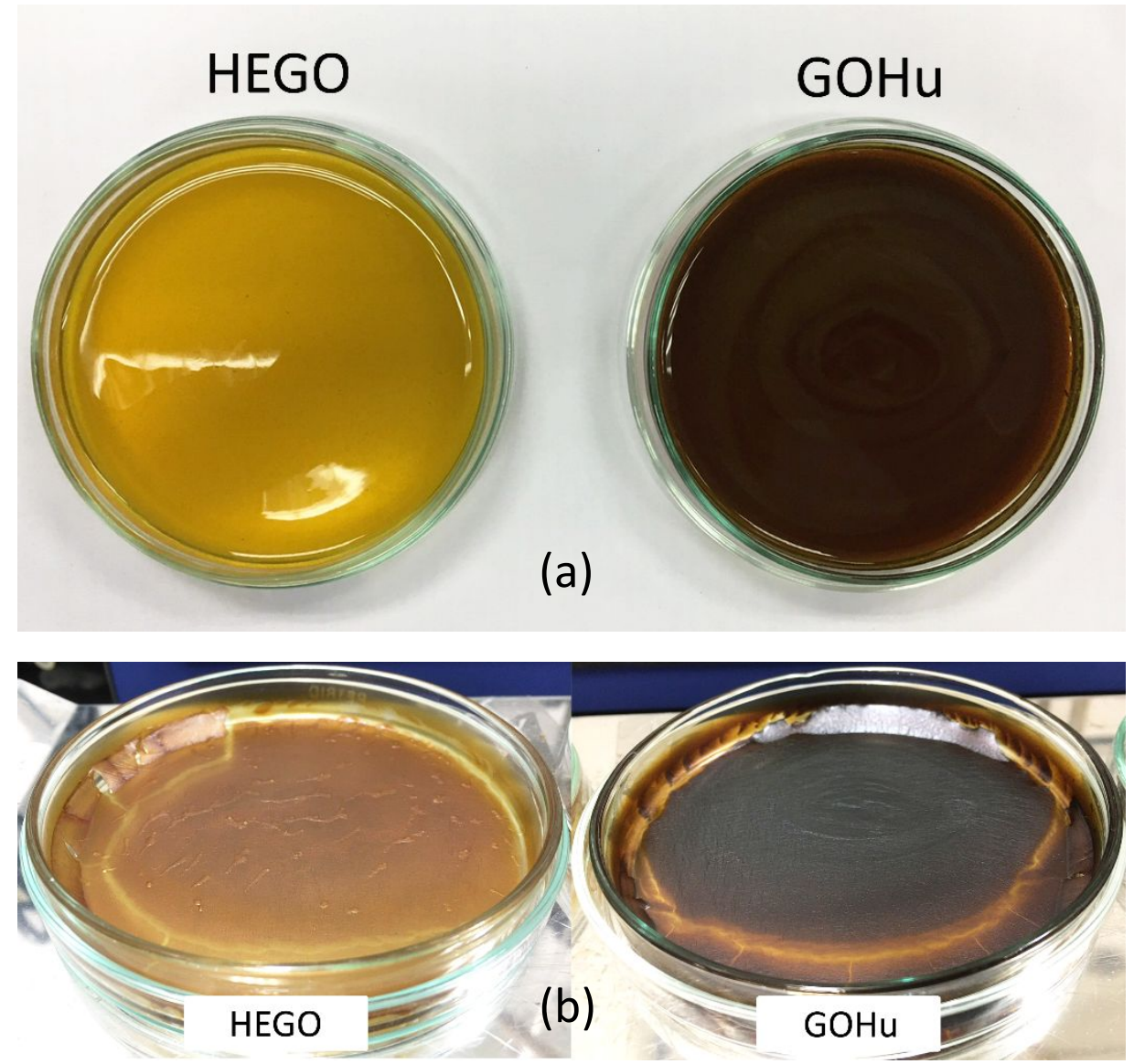

Figure S2. The HEGO and GOHu slurries (a) and dried samples (b) in petri-dishes.
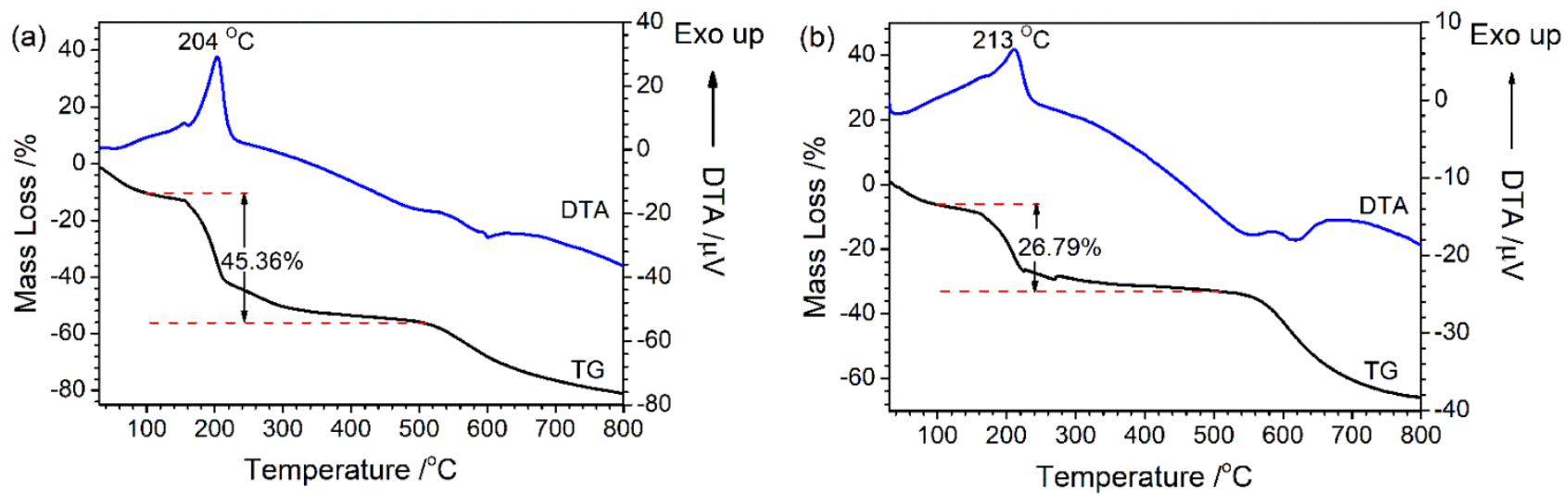

Figure S3. TGA/DTA spectra of HEGO (a) and GOHu (b). 


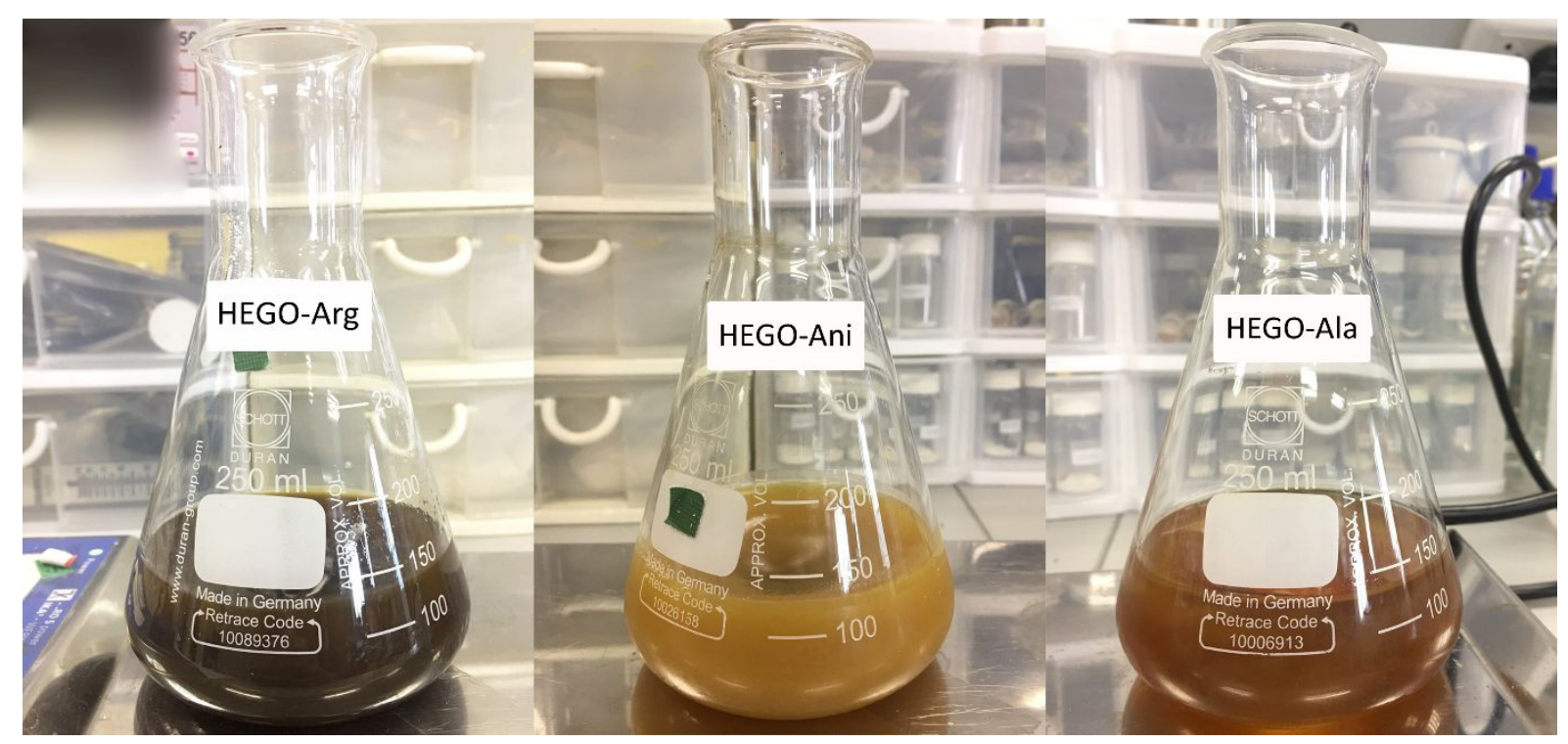

Figure S4. Experimental set-up for amine functionalization of HEGO.

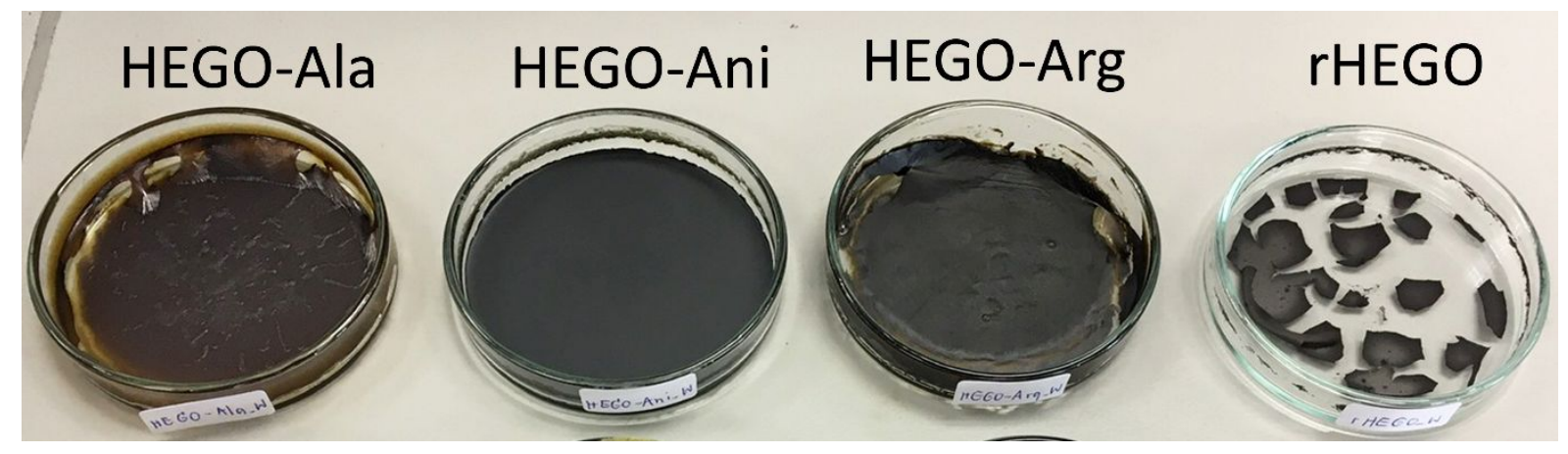

Figure S5. Dried amine functionalized HEGO samples. 


\section{SAXS analysis}

Small angle X-ray scattering (SAXS) is a technique to measure the scatterred light by a sample, which depends on its electron density or refractive index, and the obtained results can provide valuable information about size, shape, and orientation of the sample ${ }^{1}$. A material that has inhomogeneities larger that $1 \mathrm{~nm}$ can be observed with scattering patterns at small angles. The patterns are characterized by an asymptotic exponential region at small values of $\mathrm{q}$ space, where I (q) $\propto \mathrm{q}^{0}$, and by regions with a power-law decay of scattering intensity at high $\mathrm{q}$ space, where $\mathrm{I}(\mathrm{q}) \propto \mathrm{q}^{-\mathrm{n}}$. The scattering exponent $\mathrm{n}$ is corresponded to the Euclidean dimensionality. If $n=4$ is related to the three-dimensional structure such as spheres and cubes, $\mathrm{n}=2$ would be for the two-dimensional such as thin disks, and $\mathrm{n}=1$ is for onedimensional e.g. thin rods (Figure S6). However, in the case when $\mathrm{n}$ is a non-integer value between one and four, which is related to power-law distribution of scattering units, the structure of that material is estimated to be fractal geometry. In other word, that material represents the roughness surface ${ }^{2}$. The relationship between $\mathrm{q}^{-\mathrm{n}}$ value and surface shapes are shown as a categorized structural diagram in Figure S7. ${ }^{4}$

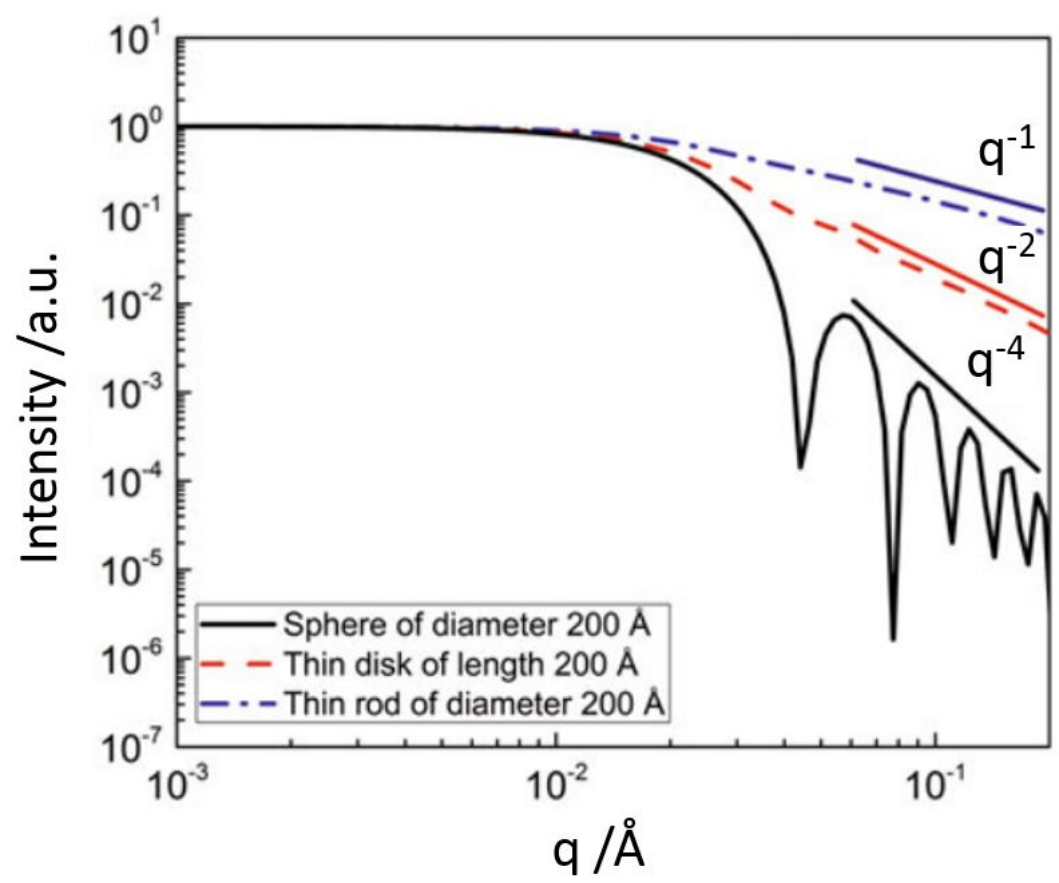

Figure S6. The SAXS patterns of a sphere (3D), thin disk (2D) and a thin rod (1D) particles. $^{3}$ 


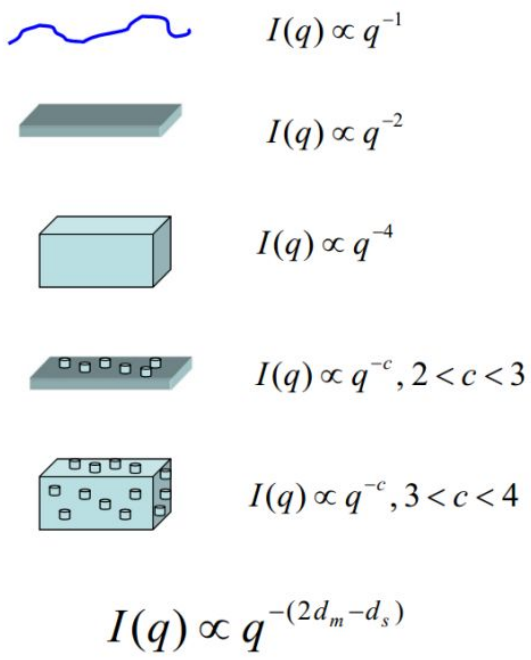

Figure S7. The relationship between $\mathrm{q}^{-\mathrm{n}}$ value and surface shapes. ${ }^{4}$
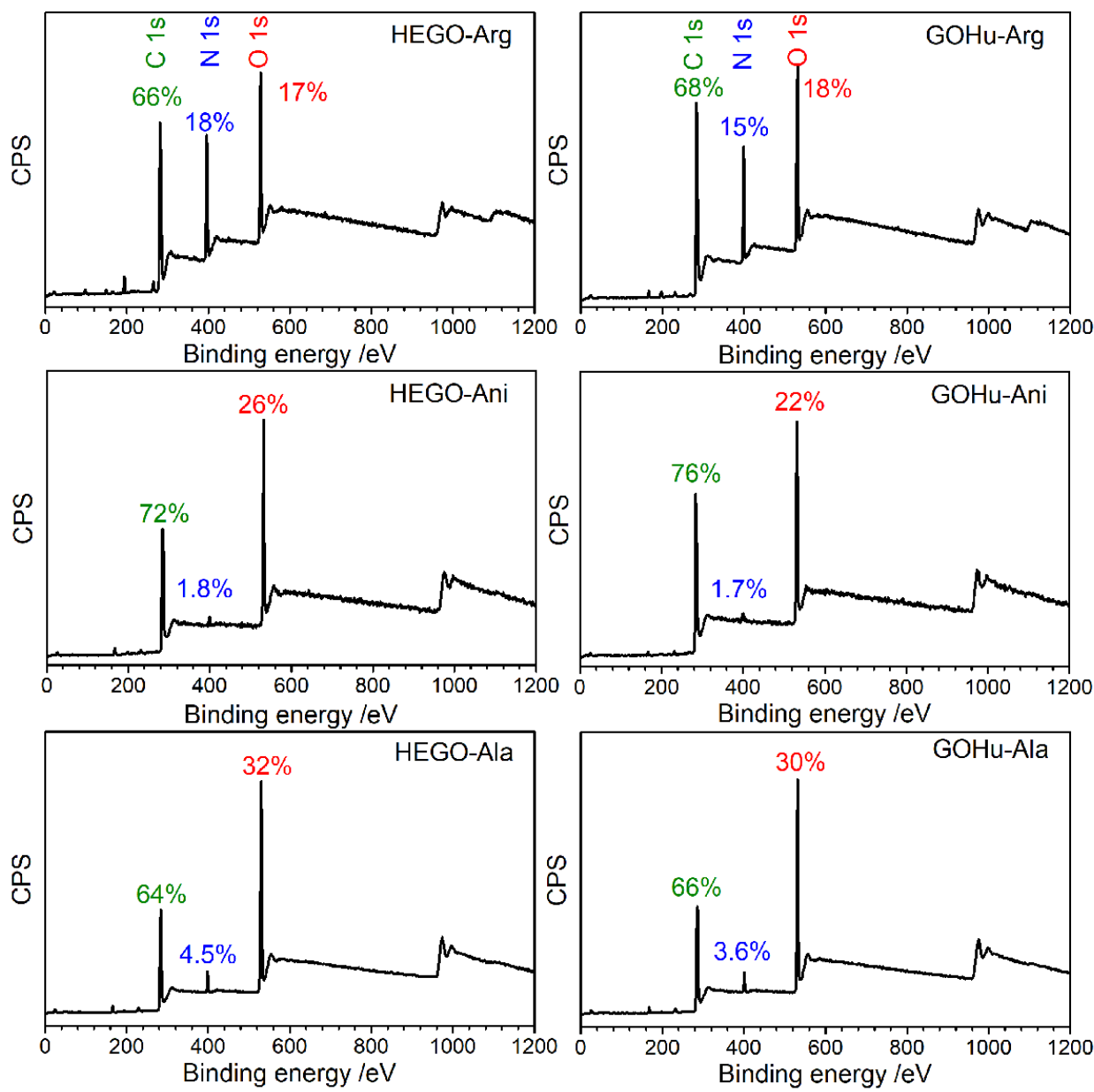

Figure S8. Wide scan XPS spectra of the functionalized GOHu and HEGO. 


\section{Neutralization test}

The neutralization test was carried out by soaking the functionalized HEGO samples with $2 \% \mathrm{v} / \mathrm{v}$ formic acid $(\mathrm{pH}=2)$ for $2 \mathrm{~h}$. The samples were then washed at least three times with DI water until $\mathrm{pH}$ was equal to 5-6. The acid-treated products were dried at room temperature for 3-5 days (Figure S9). The XPS measurement was carried out to give the results as shown in Figure S10.

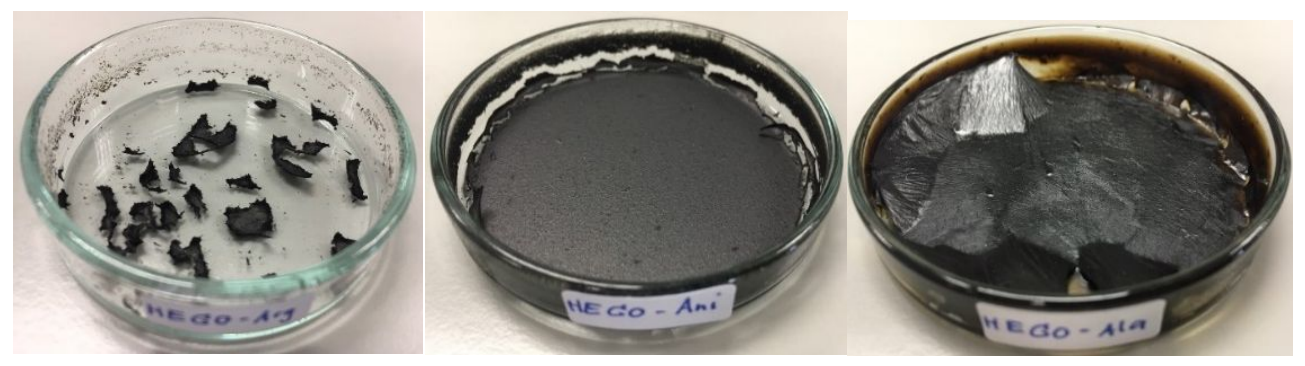

Figure S9. The pictures of the dried HEGO-Arg (a), HEGO-Ani (b), and HEGO-Ala (c) after washing with $2 \% \mathrm{v} / \mathrm{v}$ formic acid.
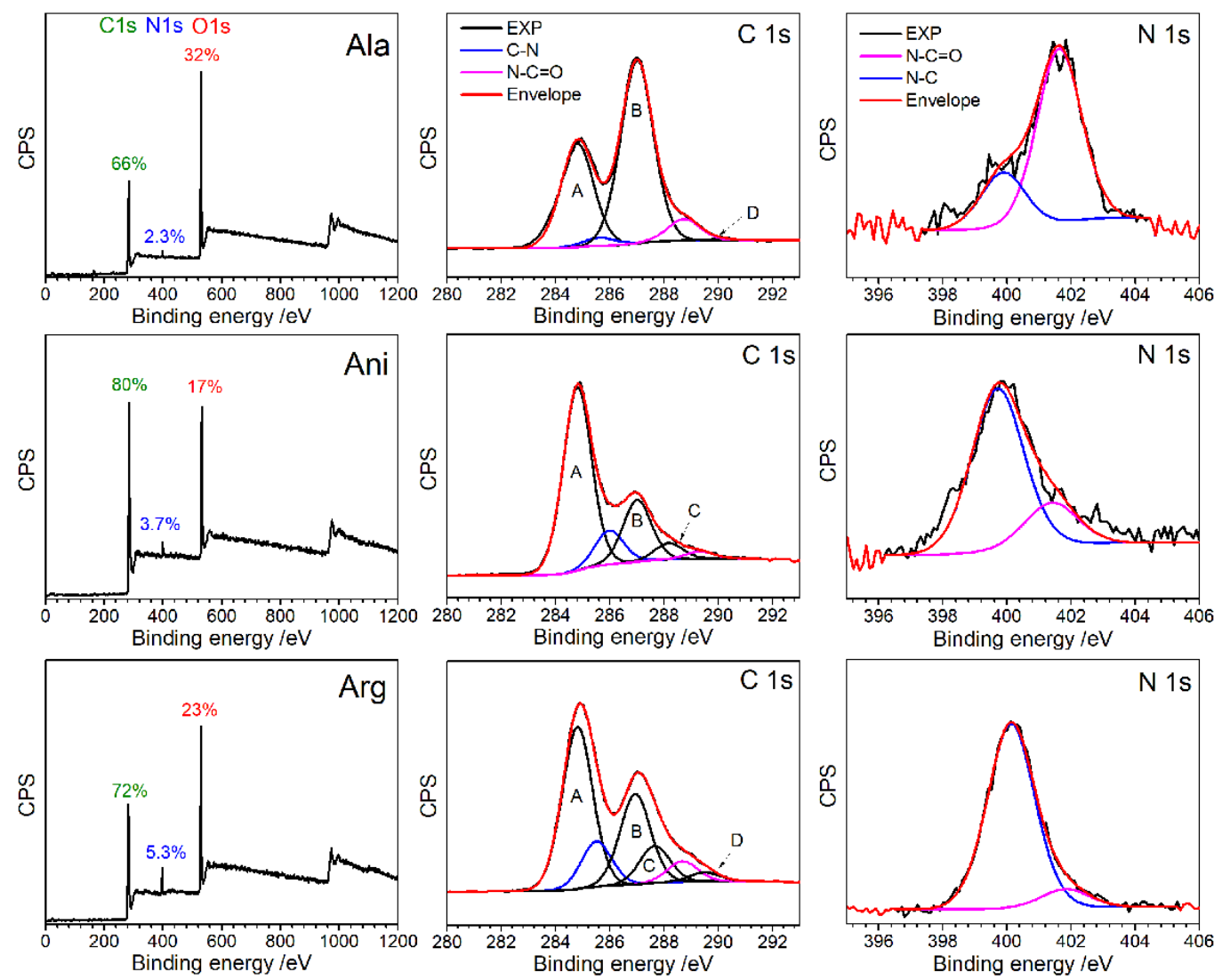

Figure S10. wide scan, C1s, and N1s of HEGO-Arg, HEGO-Ani, and HEGO-Ala after washing with $2 \% \mathrm{v} / \mathrm{v}$ formic acid. 

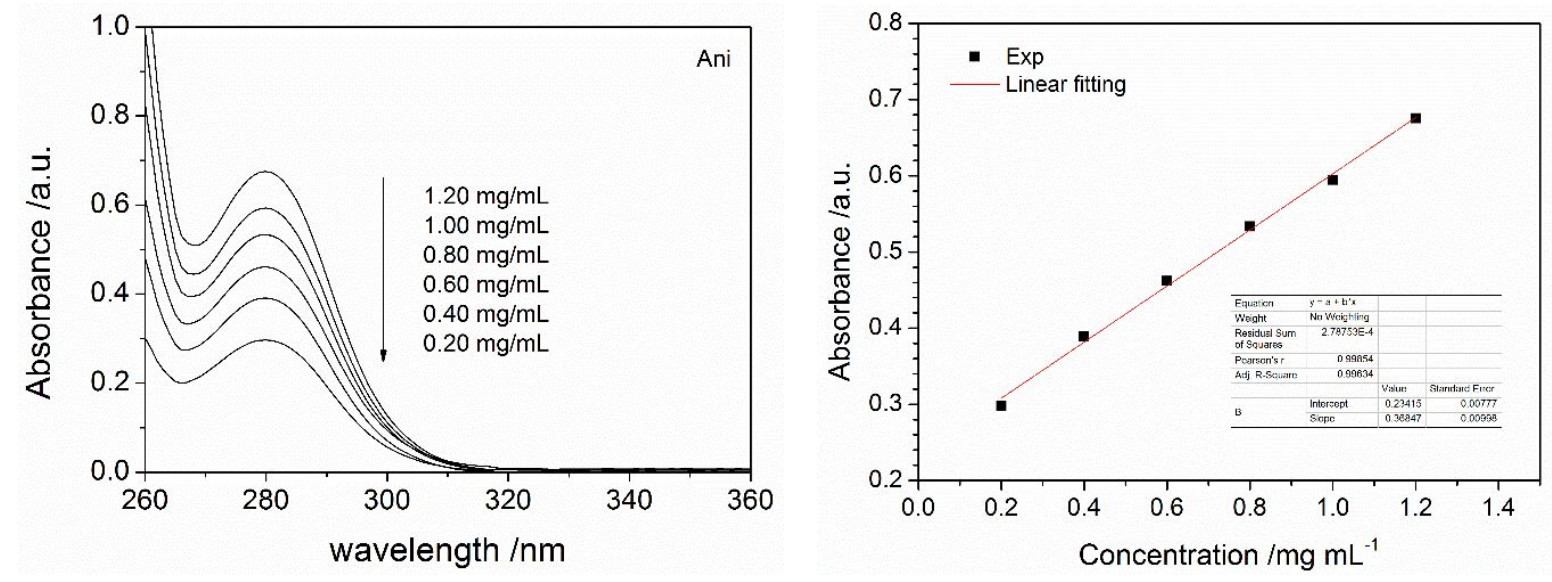

Figure S11. UV/Vis spectra and standard curve of Ani.
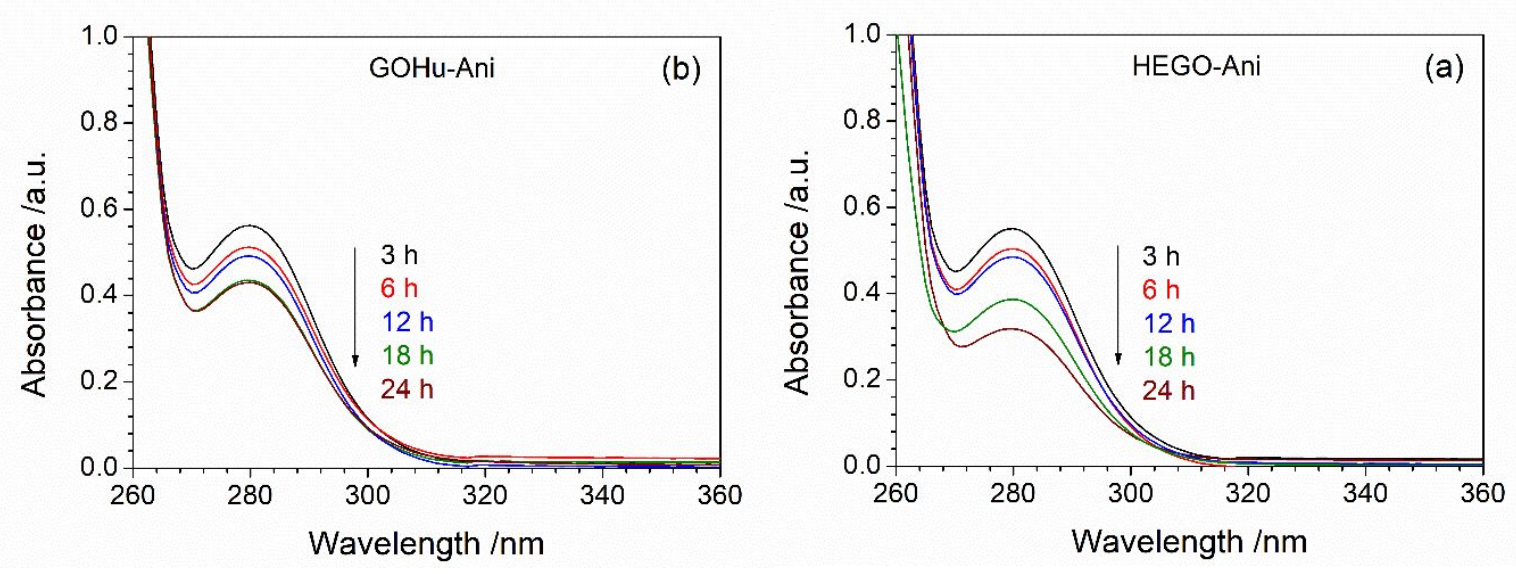

Figure S12. UV/Vis spectra of non-adsorbed Ani on HEGO (a) and GOHu (b).

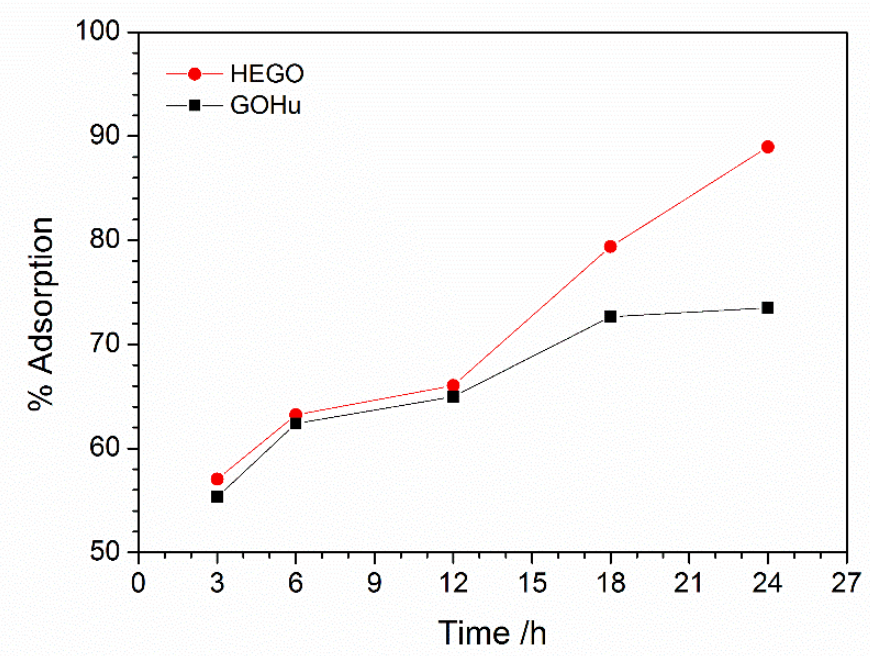

Figure S13. \%Adsorption of Ani on HEGO and GOHu. 
Table S1. XPS Data Analysis of the Amine-Functionalized Products of HEGO and GOHu

\begin{tabular}{|c|c|c|c|c|c|c|c|}
\hline \multirow[t]{2}{*}{ Components } & \multirow{2}{*}{$\begin{array}{c}\text { Binding } \\
\text { Energy /eV }\end{array}$} & \multicolumn{6}{|c|}{ Area (\%) } \\
\hline & & $\begin{array}{c}\text { HEGO- } \\
\text { Arg }\end{array}$ & $\begin{array}{c}\text { GOHu- } \\
\text { Arg }\end{array}$ & $\begin{array}{c}\text { HEGO- } \\
\text { Ani }\end{array}$ & $\begin{array}{l}\text { GOHu } \\
\text {-Ani }\end{array}$ & $\begin{array}{l}\text { HEGO- } \\
\text { Ala }\end{array}$ & $\begin{array}{l}\text { GOHu- } \\
\text { Ala }\end{array}$ \\
\hline \multicolumn{8}{|l|}{ Wide scan } \\
\hline $\mathrm{C}$ & 284.0 & 66 & 68 & 72 & 76 & 64 & 67 \\
\hline $\mathrm{O}$ & 532.0 & 17 & 18 & 26 & 22 & 32 & 30 \\
\hline $\mathrm{N}$ & 399.0 & 18 & 15 & 1.8 & 1.7 & 4.4 & 3.6 \\
\hline \multicolumn{8}{|l|}{ C 1s } \\
\hline $\mathrm{C}-\mathrm{C}$ & 284.7 & 42 & 52 & 42 & 49 & 38 & 43 \\
\hline $\mathrm{C}-\mathrm{N}$ & 285.7 & 18 & 15 & 12 & 6.3 & 3.7 & 2.2 \\
\hline $\mathrm{C}-\mathrm{O}$ & 286.4 & 17 & 14 & 37 & 38 & 49 & 46 \\
\hline $\mathrm{C}=\mathrm{O}$ & 287.7 & 11 & 8.3 & 5.6 & 2.7 & - & - \\
\hline $\mathrm{N}-\mathrm{C}=\mathrm{O}$ & 288.5 & 9.3 & 5.8 & 3.0 & 3.6 & 8.0 & 6.1 \\
\hline $\mathrm{O}-\mathrm{C}=\mathrm{O}$ & 289.1 & 2.9 & 4.5 & - & - & 1.2 & 2.8 \\
\hline \multicolumn{8}{|l|}{ O 1s } \\
\hline $\mathrm{O}=\mathrm{C} / \mathrm{O}=\mathrm{C}-\mathrm{N}$ & 531.0 & 63 & 64 & 19 & 11 & 35 & 30 \\
\hline $\mathrm{O}-\mathrm{C}$ & 532.4 & 30 & 31 & 77 & 87 & 65 & 68 \\
\hline $\mathrm{O}-\mathrm{H}$ & 534.0 & 7.4 & 4.5 & 3.9 & 2.5 & 0.6 & 2.0 \\
\hline \multicolumn{8}{|l|}{ N 1 s } \\
\hline $\mathrm{N}-\mathrm{C}$ & 399.9 & 82 & 91 & 66 & 63 & 14 & 11 \\
\hline $\mathrm{N}-\mathrm{C}=\mathrm{O}$ & 401.6 & 18 & 8.8 & 34 & 37 & 86 & 89 \\
\hline N-O (air) & 402.8 & - & - & - & - & - & - \\
\hline
\end{tabular}

Table S2. UV/Vis Data for Ani Standard Curve

\begin{tabular}{|l|c|}
\hline Conc. $\mathbf{~ m g / m L}$ & Absorbance /a.u. \\
\hline 1.20 & 0.68 \\
\hline 1.00 & 0.59 \\
\hline 0.80 & 0.53 \\
\hline 0.60 & 0.46 \\
\hline 0.40 & 0.39 \\
\hline 0.20 & 0.30 \\
\hline
\end{tabular}


Table S3. UV/Vis Analyzed Data of Ani Adsorption on HEGO and GOHu

\begin{tabular}{|r|l|c|c|c|c|}
\hline \multicolumn{1}{|c|}{ No } & sample & A & $\begin{array}{c}\text { Conc. } \\
(\mathbf{m g} / \mathbf{m L})\end{array}$ & \%Adsorption & $\begin{array}{c}\text { Adsorption efficiency } \\
\text { (mg/g) }\end{array}$ \\
\hline 1 & GOHu-Ani-24h & 0.47 & 0.53 & 74 & 740 \\
\hline 2 & GOHu-Ani-18h & 0.44 & 0.55 & 73 & 730 \\
\hline 3 & GOHu-Ani-12h & 0.49 & 0.70 & 65 & 650 \\
\hline 4 & GOHu-Ani-6h & 0.51 & 0.75 & 62 & 620 \\
\hline 5 & GOHu-Ani-3h & 0.56 & 0.89 & 55 & 550 \\
\hline 6 & HEGO-Ani-24h & 0.32 & 0.22 & 89 & 790 \\
\hline 7 & HEGO-Ani-18h & 0.39 & 0.41 & 79 & 660 \\
\hline 8 & HEGO-Ani-12h & 0.49 & 0.68 & 66 & 630 \\
\hline 9 & HEGO-Ani-6h & 0.51 & 0.74 & 63 & 570 \\
\hline 10 & HEGO-Ani-3h & 0.55 & 0.86 & 57 & 790 \\
\hline
\end{tabular}

*Initial absorbance $(\mathrm{A})$ of $\mathrm{Ani}=0.82$ at $2.0 \mathrm{mg} / \mathrm{mL}$

1 Azevedo, H. S.; da Silva, R. M. P. Self-assembling biomaterials: Molecular design, characterization and application in biology and medicine, Elsevier Ltd. 2018.

2 Anitas, E. M. Small-angle scattering (neutrons, X-rays, light) from complex systems fractal and multifractal models for interpretation of experimental data. Springer Nature Switzerland AG, Switzerland, 2019, p3-4.

3 Melnichenko, Y. B. Small-Angle Scattering from Confined and Interfacial Fluids: Applications to Energy Storage and Environmental Science. Springer International Publishing, Switzerland, 2016, p13.

4. Soontaranon, S. Synchrotron Small/Wide Angle X-ray Scattering (SAXS/WAXS). The $2^{\text {nd }}$ ASEAN Synchrotron Science Camp, 2013. 